\title{
Squalene in Human and Rat Blood Plasma*
}

\author{
DeWitt S. Goodman $†$ \\ (From the Department of Medicine, Columbia University College of Physicians \& Surgeons, \\ New York, N.Y.)
}

Squalene is a triterpenoid hydrocarbon that was first isolated from shark liver oil and was named by Tsujimoto in 1916 (1). More recently this compound has been found to be widely distributed in biological materials. Squalene has been identified and studied in plant oils and leaves $(2,3)$, in fungi (4), in tobacco and cigarette smoke (5), and in fish oils $(6,7)$. A small concentration of squalene with a rapid turnover has been identified in rat liver (8). Larger concentrations have been found in human sebum-like materials, including sebum (9-12), ear wax $(9,11)$, hair fat $(13)$, smegma (9), dermoid cyst fat $(11,14)$, and vernix caseosa (15).

Squalene is now well established as the biosynthetic intermediate immediately preceding the formation of the sterol nucleus. During the course of sterol biosynthesis squalene undergoes direct cyclization to lanosterol, which is then converted to cholesterol (16-20). Recent studies have also defined the reaction sequence between mevalonic acid and squalene (21-23) and have partly defined the unusual reaction mechanism involved in squalene biosynthesis from its immediate precursor, farnesyl pyrophosphate (24-26). The position of squalene in the biosynthetic pathway to cholesterol is indicated in Figure 1.

In the present study, small concentrations of metabolically active squalene have been identified in human and rat blood plasma.

\section{Methods}

Forty microcuries of DL-2-C $\mathrm{C}^{14}$-mevalonic acid, in solution in isotonic saline, was injected intravenously into a fasting normal young adult man. Serial blood samples were collected in syringes moistened with a solution of

* Submitted for publication November 13, 1963; accepted March 12, 1964.

Supported by research grant AM-05968 from the National Institutes of Health.

† Recipient of Career Scientist Award of the Health Research Council of the City of New York under contract I-399. heparin and were immediately placed on ice. The samples were centrifuged at $2,000 \times g$ for 45 minutes at $4^{\circ}$ $\mathrm{C}$, and the plasma was removed. Small samples of plasma were extracted immediately. Larger volumes of plasma ( 28 to $38 \mathrm{ml}$ per sample) were used for the serial separation of lipoprotein classes as described by Havel, Eder, and Bragdon (27). Three lipoprotein fractions were collected from each sample by ultracentrifugation at densities (before centrifugation) of 1.019, 1.063, and 1.21 .

Ten male Sprague-Dawley rats weighing 175 to $200 \mathrm{~g}$ each were fasted overnight, and each was injected intravenously with $1 \mathrm{ml}$ of a solution containing $25 \mu \mathrm{c} \mathrm{DL}-2-$ $\mathrm{C}^{14}$-mevalonic acid per $\mathrm{ml}$ in isotonic saline. At specified time intervals the animals were anesthetized with ether, and as much blood as possible, from 7 to $8 \mathrm{ml}$, was withdrawn from the abdominal aorta into syringes moistened with heparin. The livers were immediately perfused in situ with ice-cold isotonic saline via the superior vena cava and were then excised and placed on ice. Blood and liver samples were combined into two groups of five each for further processing. In one group (" $\mathrm{A}$ "), all samples were collected after relatively short time intervals ( 37 to 41 minutes; average, 39 minutes). In the other group ("B"), the samples were all collected between 2 hours 11 minutes and 2 hours 14 minutes (average, 2 hours 13 minutes). The plasma and liver samples from each group were combined into a single sample. Small volumes $(2.5 \mathrm{ml}$ for $\mathrm{A}, 3.0 \mathrm{ml}$ for $\mathrm{B})$ of plasma were extracted immediately, and larger volumes (16 $\mathrm{ml}$ for each) were used for lipoprotein separations as described above. Livers were homogenized with 2.5

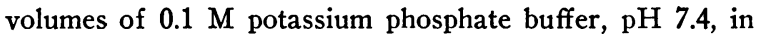
a Potter-Elvehjem homogenizer, and portions of each homogenate were then extracted.

The plasma, lipoprotein, and liver samples were each extracted with 25 vol $\mathrm{CHCl}_{8}: \mathrm{MeOH}, 2: 1$ (vol/vol). The extraction mixture was split into two phases by addition of 5 vol $0.05 \% \mathrm{H}_{2} \mathrm{SO}_{4}$ and the entire $\mathrm{CHCl}_{3}$ phase collected and evaporated to dryness under a stream of nitrogen. The total lipid so obtained was separated into hydrocarbon, cholesterol ester, and free cholesterol (plus triglyceride) fractions by silicic acid column chromatography as described elsewhere (28). The column separations were standardized to ensure a quantitative recovery of squalene in the hydrocarbon fraction, with no contamination by cholesterol esters.

Radioassay was carried out with a Packard liquid scintillation spectrometer, using $0.5 \%$ diphenyloxazole in toluene as solvent. 


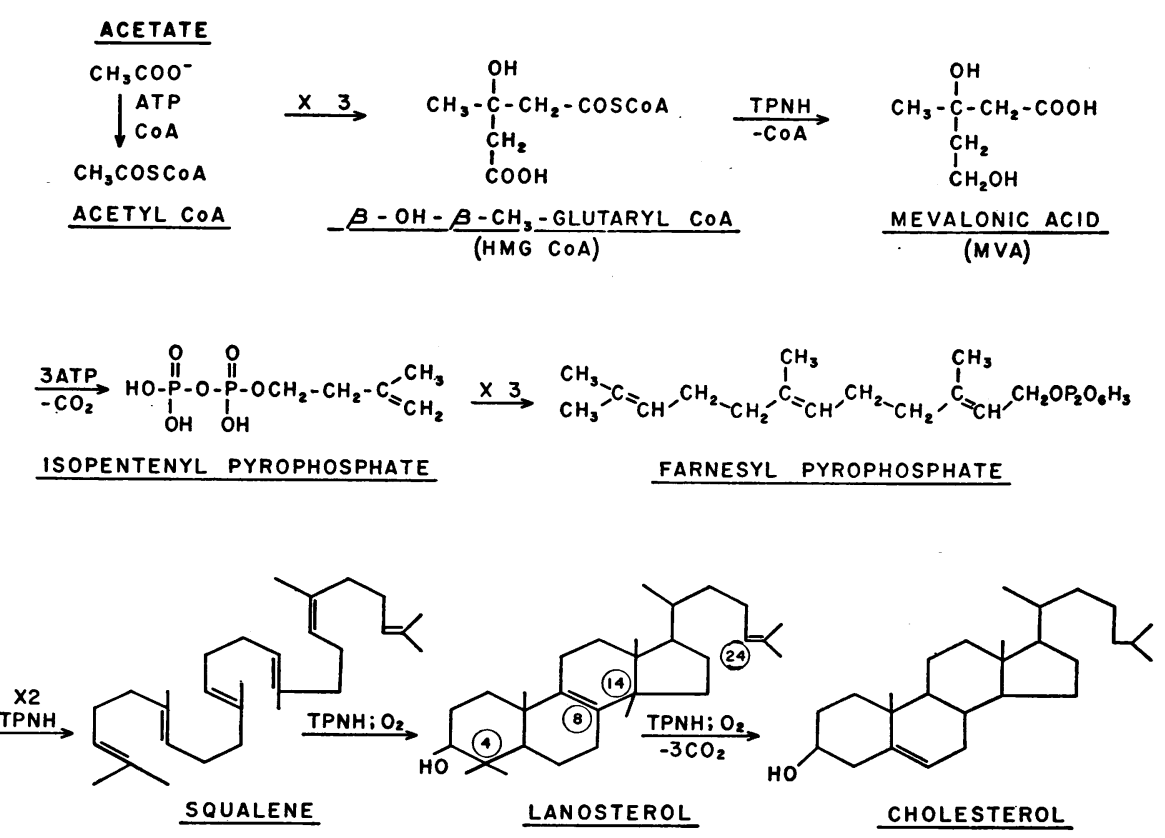

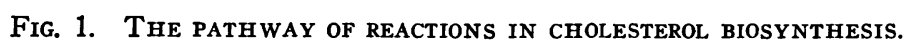

The thiourea adduct of squalene was prepared, and the squalene later regenerated, as described by Goodman and Popják (23). Carrier pure squalene 1 was added before preparation of the adduct.

Thin-layer chromatography (TLC) of squalene was carried out on thin layers of silica gel $\mathrm{G}$ using benzene: hexane, 3:97, as ascending solvent. The plates were impregnated with rhodamine $6 \mathrm{G}$ to permit ready visualization under ultraviolet light. After chromatography of carrier squalene the plates showed a single narrow squalene band of $R_{f}$ approximately 0.5 , with several very faint bands of greater $R_{\mathbf{r}}$. TLC of sterols was performed as described by Avigan, Goodman, and Steinberg (29), using benzene: ethyl acetate, 5:1. Carrier lanosterol-dihydrolanosterol 2 was added to the free sterol samples of biological origin before chromatography. The developed plates showed widely separated bands of lanosterol-dihydrolanosterol ( $R_{f}$ ca. 0.75$)$ and cholesterol ( $R_{\mathfrak{f}}$ ca. 0.6$)$. Elution of various portions of the plates was accomplished by scraping the desired zone on to a filter funnel and eluting with $\mathrm{CHCl}_{3}$.

Gas-liquid chromatography (GLC) was performed with a Barber-Colman model 25 chromatograph equipped with a radium-containing argon ionization detector. A glass coil column, 8 feet $\times \frac{1}{4}$ inch, containing $1 \%$ SE30 on Anakrom ABS was used. The column temperature was $225^{\circ}$ and the cell temperature $245^{\circ}$. The cell operated at $900 \mathrm{v}$. The argon pressure was 35 pounds per square

1 Purchased from Eastman Organic Chemicals, Rochester, N. Y.

2 Purchased as "lanosterol" from California Corp. for Biochemical Research, Los Angeles, Calif. inch. Pure squalene, cholesterol, 24,25-dihydrolanosterol, and lanosterol emerged with retention times of $20.8,39.5$, 60.6 , and 66.6 minutes, respectively. Calibration with pure squalene showed that the area of the squalene peak was proportional to the mass of squalene injected on to the column, over a wide range of mass.

\section{Results}

Human. Assay of the silicic acid column fractions of human lipoprotein lipid for $\mathrm{C}^{\mathbf{1 4}}$ revealed that only the very low density $(<1.019)$ lipoprotein samples contained significant radioactivity in the hydrocarbon fractions. None of the hydrocarbon fractions from any of the samples of the two higher density lipoproteins contained

TABLE I

Time-course of the distribution of radioactivity in human very low density lipoprotein lipid after 2-C 14-mevalonate

\begin{tabular}{|c|c|c|c|c|}
\hline \multirow[b]{2}{*}{ Time } & \multirow[b]{2}{*}{ Total Cu } & \multicolumn{3}{|c|}{ Distribution of recovered C14 } \\
\hline & & $\begin{array}{l}\text { Hydro- } \\
\text { carbons }\end{array}$ & $\begin{array}{l}\text { Choles- } \\
\text { terol } \\
\text { esters }\end{array}$ & $\begin{array}{c}\text { Free } \\
\text { choles- } \\
\text { terol }\end{array}$ \\
\hline hours & $\underset{\text { ml plasma }}{c p m / 100}$ & $\%$ & $\%$ & $\%$ \\
\hline $\begin{array}{r}1.83 \\
2.92 \\
4.83 \\
7.75 \\
10.83\end{array}$ & $\begin{array}{r}9,086 \\
15,372 \\
11,146 \\
8,657 \\
7,446\end{array}$ & $\begin{array}{r}11.6 \\
5.8 \\
2.1 \\
0.7 \\
0.1\end{array}$ & $\begin{array}{r}3.6 \\
8.1 \\
18.2 \\
32.8 \\
38.7\end{array}$ & $\begin{array}{l}84.7 \\
86.1 \\
79.6 \\
66.5 \\
61.2\end{array}$ \\
\hline
\end{tabular}


TABLE II

Radioactivity of the hydrocarbon fractions of rat plasma and plasma lipoproteins after 2-C ${ }^{14}$-mevalonate

\begin{tabular}{|c|c|c|c|c|}
\hline & \multicolumn{2}{|c|}{$\begin{array}{l}\text { Total cpm } \times 10^{-6} \\
\text { per } 100 \mathrm{ml} \text { plasma } \\
\end{array}$} & \multicolumn{2}{|c|}{$\begin{array}{c}\% \text { of total } \mathrm{C}^{14} \text { in } \\
\text { hydrocarbon fraction }\end{array}$} \\
\hline & $\begin{array}{c}\text { Sample } \mathrm{A} \\
\text { (0.65 hour) }\end{array}$ & $\begin{array}{c}\text { Sample B } \\
\text { (2.22 hours) }\end{array}$ & $\begin{array}{l}\text { Sample A } \\
\text { (0.65 hour) }\end{array}$ & $\begin{array}{l}\text { Sample B } \\
\text { (2.22 hours) }\end{array}$ \\
\hline Whole plasma & 1.229 & 2.046 & 9.1 & 0.6 \\
\hline \multicolumn{5}{|c|}{ Lipoproteins of density: } \\
\hline $\begin{array}{l}<1.019 \\
1.019-1.063 \\
1.063-1.21\end{array}$ & $\begin{array}{l}0.422 \\
0.166 \\
0.587\end{array}$ & $\begin{array}{l}0.387 \\
0.393 \\
1.124\end{array}$ & $\begin{array}{r}14.2 \\
3.7 \\
2.6\end{array}$ & $\begin{array}{l}1.1 \\
0.2 \\
0.3\end{array}$ \\
\hline
\end{tabular}

more than $0.5 \%$ of the total radioactivity of the sample. The results observed with the very low density lipoprotein samples are presented in Table I. At the earliest time interval studied (1.83 hours) a considerable fraction of the total radioactivity was found in the hydrocarbon fraction. With increasing time the relative amount of radioactivity in this fraction decreased progressively; by 10.8 hours only $0.1 \%$ of the radioactivity was found in this fraction. The time course of the distribution of radioactivity shown in Table $I$ is consistent with the conclusion that the radioactivity in the hydrocarbon fraction resided in a compound on the biosynthetic pathway from $\mathrm{C}^{14}$ mevalonic acid to cholesterol. The only known compound on this pathway that appears in the hydrocarbon fraction after silicic acid chromatography is squalene.

Further chromatographic identification of the hydrocarbon radioactivity was attempted by TLC. Portions of the 1.8- and the 4.8-hour hydrocarbon samples from the very low density lipoproteins were chromatographed, together with $1 \mathrm{mg}$ carrier squalene, as described above. With each sample, the narrow squalene band was scraped from the plate and eluted. The entire remainder of the plate, from the origin to the solvent front, was also scraped and eluted. Assay of the eluates for $\mathrm{C}^{14}$ showed that, for the two samples, respectively, 83 and $86 \%$ of the recovered radioactivity were found in the squalene zone.

Carrier squalene $(20 \mu \mathrm{g})$ was added to a portion of the 2.9-hour hydrocarbon sample, and the thiourea adduct formed. The squalene regenerated from the adduct contained $77 \%$ of the expected radioactivity.

Rat. Silicic acid column chromatography of the fipid samples from rat plasma revealed the presence of considerable radioactivity in the hydrocarbon fraction of the early sample (A) but very little in the hydrocarbon fraction of the later sample (B). The results are presented in Table II. As with the human subject, most of the hydrocarbon radioactivity was found associated with the very low density lipoprotein.

Carrier squalene $(50 \mu \mathrm{g})$ was added to portions of the hydrocarbon fractions from each of the lipoprotein fractions of plasma sample A and from the very low density lipoprotein fraction of plasma sample B. After formation of the thiourea adduct and regeneration of the squalene, more than $90 \%$ of the radioactivity was recovered, in each sample, in the regenerated squalene.

Gas chromatographic estimation of squalene concentration. Portions of the very low density lipoprotein hydrocarbon fractions from the 2.9hour sample of the human subject and from rat sample A, were saponified and the nonsaponifiables analyzed by GLC. Similar results were obtained with both the human and rat samples. Both samples showed a single major peak with retention time identical to that of pure squalene. This peak was preceded by a series of much smaller peaks and followed by only one definite very small peak (retention time, $1.36 \times$ squalene). No further peaks emerged during a total chromatography time of 85 minutes. The identities of the small peaks with retention times other than that of squalene are not known; these peaks may represent impurities accumulated during the processing of the samples, or they may represent unknown compounds of biological origin present in the original lipoprotein samples.

An estimate was made of the squalene concentration in plasma by assuming that the gas chromatographic peak with retention time identical 
to that of squalene represented squalene derived from the lipoprotein sample. The area of this peak was then compared to the areas observed with known amounts of pure squalene, on GLC under identical conditions. This provided an estimate of squalene mass, which could be related to the volume of plasma from which this squalene was derived. These calculations indicated that the concentration of squalene in the very low density lipoprotein fraction was approximately $29 \mu \mathrm{g}$ per $100 \mathrm{ml}$ human plasma and approximately $36 \mu \mathrm{g}$ per $100 \mathrm{ml}$ rat plasma.

Lanosterol. Preliminary evidence was also obtained for the presence of lanosterol in plasma. Portions of the free sterol fractions of human and rat plasma were chromatographed together with carrier lanosterol as described under Methods. The developed plates were scraped and eluted in three zones: lanosterol, an intermediate zone between lanosterol and cholesterol, and cholesterol. This procedure is identical with that employed in the study of the time course of cholesterol biosynthesis in rat liver (20). As discussed elsewhere (20) the lanosterol TLC zone should contain 30-carbon sterols, the intermediate zone 28- and 29-carbon sterols, and the cholesterol zone 27 -carbon sterols. The results obtained in the present study are presented in Table III. In the rat plasma and rat liver samples, the early sample (A) showed significant radioactivity in both the lanosterol and intermediate TLC zones. The later (B) samples showed significantly less radioactivity in these zones. The amounts of radioactivity found in the lanosterol and intermediate zones in the A samples were much greater than the technical error of the chromatographic procedure. Previous studies have indicated that such lanosterol zone radioactivity from liver nonsaponifiables actually resides in $\mathrm{C}^{14}$-lanosterol and that the intermediate zone radioactivity from liver probably resides in 28-carbon sterols (20). It is thus reasonable to presume that the lanosterol and intermediate zone radioactivity found in plasma also resided in corresponding sterol precursors of cholesterol. The time course of the distribution of radioactivity shown in Table III is consistent with this hypothesis.

Relatively less radioactivity was found in the lanosterol and intermediate TLC zones with the human plasma samples. The relative amount of radioactivity in these TLC zones was, however, greatest in the earliest plasma sample and decreased progressively with time (see Table III). This time course suggests that, as with the rat plasma, the lanosterol and intermediate zone radioactivity actually resided in sterol precursors of cholesterol present in human plasma. Analysis of the three lipoprotein fractions from the 2.9hour sample (Table III) revealed a similar distribution of radioactivity in all three lipoproteins. This suggests that the sterol precursors of cholesterol were comparably present in all lipoprotein fractions.

An attempt was made to identify lanosterol in plasma by GLC. Approximately half the free sterol fractions from the three lipoproteins corresponding to rat plasma sample $A$, and from those of the third (4.8-hour) human plasma sample, were each combined and subjected to TLC without the addition of carrier lanosterol. After chromatography the area of each plate just above the cholesterol zone, and almost to the solvent front, was scraped and eluted. This area included the intermediate and lanosterol TLC zones, as determined by standard spots run on the same plates. Portions of each eluate were then analyzed by GLC. The chromatogram from each sample showed a series of unidentified very

TABLE III

Distribution of radioactivity in the free sterols of human and rat plasma and rat liver

\begin{tabular}{|c|c|c|c|}
\hline \multirow[b]{2}{*}{ Sample and time } & \multicolumn{3}{|c|}{$\begin{array}{l}\% \text { of total sterol } \mathrm{C}^{14} \text { in thin- } \\
\text { layer chromatography zone }\end{array}$} \\
\hline & $\underset{\text { terol }}{\text { Lanos- }}$ & $\begin{array}{l}\text { Inter- } \\
\text { mediate }\end{array}$ & $\begin{array}{c}\text { Choles- } \\
\text { terol }\end{array}$ \\
\hline \multicolumn{4}{|l|}{ Human whole plasma } \\
\hline $\begin{array}{l}1.83 \text { hour } \\
2.92 \text { hour } \\
4.83 \text { hour }\end{array}$ & $\begin{array}{l}3.0 \\
2.4 \\
1.4\end{array}$ & $\begin{array}{l}2.0 \\
1.4 \\
0.7\end{array}$ & $\begin{array}{l}95.0 \\
96.1 \\
97.9\end{array}$ \\
\hline \multicolumn{4}{|c|}{ Human plasma lipoproteins, 2.92-hour sample } \\
\hline $\begin{aligned} \rho & <1.019 \\
1.019<\rho & <1.063 \\
1.063<\rho & <1.21\end{aligned}$ & $\begin{array}{l}2.6 \\
2.4 \\
2.7\end{array}$ & $\begin{array}{l}1.5 \\
1.4 \\
1.2\end{array}$ & $\begin{array}{l}95.9 \\
95.2 \\
96.1\end{array}$ \\
\hline \multicolumn{4}{|l|}{ Rat whole plasma } \\
\hline $\begin{array}{l}0.65 \text { hour }(\mathrm{A}) \\
2.22 \text { hour }(\mathrm{B})\end{array}$ & $\begin{array}{l}7.9 \\
2.2\end{array}$ & $\begin{array}{l}4.8 \\
1.8\end{array}$ & $\begin{array}{l}87.3 \\
96.0\end{array}$ \\
\hline \multicolumn{4}{|l|}{ Rat liver } \\
\hline $\begin{array}{l}0.65 \text { hour }(\mathrm{A}) \\
2.22 \text { hour }(\mathrm{B})\end{array}$ & $\begin{array}{l}6.1 \\
2.3\end{array}$ & $\begin{array}{l}4.2 \\
2.0\end{array}$ & $\begin{array}{l}89.9 \\
95.7\end{array}$ \\
\hline
\end{tabular}


early peaks and a small peak with retention time corresponding to that of cholesterol. There were no peaks discernible at retention times corresponding to lanosterol or dihydrolanosterol, or at retention times that might be expected for 28- or 29carbon sterols. The sensitivity of the instrument was such that approximately $0.5 \mu \mathrm{g}$ of either lanosterol or dihydrolanosterol should have been definitely detected. By relating the GLC sample size to the corresponding volume of plasma, it was possible to estimate that the concentration of free lanosterol in plasma, if present, must be less than $40 \mu \mathrm{g}$ per $100 \mathrm{ml}$ in man and less than $35 \mu \mathrm{g}$ per $100 \mathrm{ml}$ in the rat.

\section{Discussion}

The data presented here demonstrate the presence of small amounts of metabolically active squalene in human and rat plasma. Radioactivity rapidly appeared in, and then subsequently disappeared from, this squalene pool after intravenous $\mathrm{C}^{14}$-mevalonate. Identification of the radioactivity as residing in squalene included its chromatographic behavior on silicic acid columns and thin-layer plates and its formation, with carrier squalene, of a thiourea adduct. These properties provide a fairly confident, albeit inferential, identification. There is no known metabolite of mevalonic acid other than squalene that would exhibit this combination of properties. Most of the labeled plasma squalene was found associated with the very low density $(<1.019)$ lipoprotein fraction in both man and the rat. The concentration of squalene in the plasma very low density lipoprotein was estimated by gas-liquid chromatography to be approximately 30 to $35 \mu \mathrm{g}$ squalene per $100 \mathrm{ml}$ plasma in both species.

The rapid appearance and disappearance of radioactivity in plasma squalene indicated that this squalene was in close equilibrium with the tissue squalene pool involved in cholesterol biosynthesis from $\mathrm{C}^{14}$-mevalonate. This tissue pool was undoubtedly located in the liver, which is the major organ involved in cholesterol biosynthesis. Langdon and Bloch (8) have estimated that the concentration of squalene in rat liver is of the order of $25 \mu \mathrm{g}$ per $\mathrm{g}$ of tissue. Although this is probably a maximal estimate [see (8)], it does indicate that the squalene pool in plasma is much smaller than the liver pool with which it is apparently in close equilibrium.

Preliminary data have also been presented that suggest the presence of small amounts of lanosterol and of other sterol precursors of cholesterol in plasma. These sterols were apparently also in close equilibrium with their corresponding liver pools. The concentration of free lanosterol, if present, was less than $35 \mu \mathrm{g}$ per $100 \mathrm{ml}$ plasma.

\section{Summary}

Radioactive squalene has been observed transiently in human and rat plasma after the intravenous administration of $\mathrm{C}^{\mathbf{1 4}}$-mevalonic acid. Identification of the labeled squalene included its chromatographic behavior and its formation of a thiourea adduct. Most of the labeled squalene was associated with the very low density (density $<$ 1.019) lipoprotein fraction, in which its concentration was estimated to be approximately 30 to $35 \mu \mathrm{g}$ per $100 \mathrm{ml}$ plasma in both species. The plasma squalene pool appears to be in close equilibrium with the larger liver squalene pool.

Preliminary evidence has also been obtained that suggests the presence of small amounts of lanosterol in plasma.

\section{Acknowledgments}

The expert assistance of Mr. T. Shiratori and Miss C. Goldman is gratefully acknowledged.

\section{References}

1. Tsujimoto, M. A highly unsaturated hydrocarbon in shark liver oil. J. ind. Eng. Chem. 1916, 8, 889.

2. Dickhart, W. The squalene contents of various oils. Amer. J. Pharm. 1955, 127, 359.

3. Alam, S. Q., J. Brossard, and G. MacKinney. Detection and estimation of squalene in leaves. $\mathrm{Na}$ ture (Lond.) 1962, 194, 479.

4. Wirth, J. C., T. Beesley, and W. Miller. The isolation of a unique sterol from the mycelium of a strain of Trichophyton rubrum. J. invest. Derm. 1961, 37, 153.

5. Rodgman, A., L. C. Cook, and S. S. Mims. The composition of cigarette smoke. V. Solanesenes. J. organ. Chem. 1961, 26, 497.

6. Karnovsky, M. L., W. S. Rapson, H. M. Schwartz, M. Black, and N. J. van Vensburg. South African fish products. XXVII. The composition of the liver oils of the basking shark and the spiny shark. J. Soc. chem. Ind. 1948, 67, 104. 
7. Sorrels, M. F., and R. Reiser. Identification of some marine oil constituents by chromatography. J. Amer. Oil chem. Soc. 1957, 34, 131.

8. Langdon, R. G., and K. Bloch. The biosynthesis of squalene. J. biol. Chem. 1953, 200, 129.

9. Sobel, H. Squalene in sebum and sebum-like materials. J. invest. Derm. 1949, 13, 333.

10. MacKenna, R. M. B., V. R. Wheatley, and A. Wormall. The composition of the surface skin fat (sebum) from the human forearm. J. invest. Derm. 1950, 15, 33.

11. Wheatley, V. R. Studies of serum. 4. The estimation of squalene in sebum and sebum-like materials. Biochem. J. 1953, 55, 637.

12. Haati, E. Major lipid constituents of human skin surface with special reference to gas chromatographic methods. Scand. J. clin. Lab. Invest. 1961, 13 (suppl. 59).

13. Nicolaides, N., and S. Rothman. Chemical composition of human hair fat. I. Squalene-cholesterol relation in children and adults. $\mathrm{J}$. invest. Derm. 1952, 19, 389.

14. Wheatley, V. R. Nature of ovarian dermoid cyst fat. Nature (Lond.) 1951, 168, 1128.

15. Cmelik, S., N. Petrak-Longhino, and F. Mihelie. Uber die unverseifbaren Lipoide der Vernix caseosa. Biochem. Z. 1952, 322, 355.

16. Clayton, R. B., and Bloch, K. The biological conversion of lanosterol to cholesterol. J. biol. Chem. 1956, 218, 319.

17. Schneider, P. B., R. B. Clayton, and K. Bloch. Synthesis of lanosterol in vivo. J. biol. Chem. 1957, 224, 175.

18. Tchen, T. T., and K. Bloch. On the conversion of squalene to lanosterol in vitro. J. biol. Chem. 1957, 226, 921.

19. Olson, J. A., Jr., M. Lindberg, and K. Bloch. On the demethylation of lanosterol to cholesterol. J. biol. Chem. 1957, 226, 941.

20. Goodman, DeW. S., J. Avigan, and D. Steinberg. Studies of cholesterol biosynthesis. V. The time course and pathway of the later stages of cho- lesterol biosynthesis in the livers of intact rats. J. biol. Chem. 1963, 238, 1287.

21. Bloch, K., S. Chaykin, A. H. Phillips, and A. De Waard. Mevalonic acid pyrophosphate and isopentenylpyrophosphate. J. biol. Chem. 1959, 234, 2595.

22. Lynen, F., B. W. Agranoff, H. Eggerer, U. Henning, and E. M. Möslein. $\boldsymbol{\gamma}, \boldsymbol{\gamma}$-Dimethyl-allyl-pyrophosphat und Geranyl-pyrophosphat, biologische Vorstufen des Squalens. Angew. Chem. 1959, 71, 657.

23. Goodman, DeW. S., and G. Popják. Studies on the biosynthesis of cholesterol. XII. Synthesis of allyl pyrophosphates from mevalonate and their conversion into squalene with liver enzymes. J. Lipid Res. 1960, 1, 286.

24. Popják, G., DeW. S. Goodman, J. W. Cornforth, R. H. Cornforth, and R. Ryhage. Studies on the biosynthesis of cholesterol. XV. Mechanism of squalene biosynthesis from farnesyl pyrophosphate and from mevalonate. J. biol. Chem. 1961, 236, 1934.

25. Cornforth, J. W., R. H. Cornforth, C. Donninger, G. Popják, G. Ryback, and G. J. Schroepfer, Jr. Stereospecific insertion of hydrogen atom into squalene from reduced nicotinamide-adenine dinucleotides. Biochem. biophys. Res. Commun. 1963, $11,129$.

26. Samuelsson, B., and DeW. S. Goodman. Stereochemistry of the hydrogen transfer to squalene during its biosynthesis from farnesyl pyrophosphate. Biochem. biophys. Res. Commun. 1963, 11, 125.

27. Havel, R. J., H. A. Eder, and J. H. Bragdon. The distribution and chemical composition of ultracentrifugally separated lipoproteins in human serum. J. clin. Invest. 1955, 34, 1345.

28. Goodman, DeW. S., and T. Shiratori. The fatty acid composition of human plasma lipoprotein fractions. J. Lipid Res. 1964, July, in press.

29. Avigan, J., DeW. S. Goodman, and D. Steinberg. Thin-layer chromatography of sterols and steroids. J. Lipid Res. 1963, 4, 100. 